\title{
Expression of Trichoderma reesei cellulases CBHI and EGI in Ashbya gossypii
}

\author{
Orquídea Ribeiro • Marilyn Wiebe • Marja Ilmén • \\ Lucília Domingues • Merja Penttilä
}

Received: 26 January 2010 /Revised: 8 April 2010 /Accepted: 9 April 2010 / Published online: 27 April 2010

(C) Springer-Verlag 2010

\begin{abstract}
To explore the potential of Ashbya gossypii as a host for the expression of recombinant proteins and to assess whether protein secretion would be more similar to the closely related Saccharomyces cerevisiae or to other filamentous fungi, endoglucanase I (EGI) and cellobiohydrolase I (CBHI) from the fungus Trichoderma reesei were successfully expressed in A. gossypii from plasmids containing the two micron sequences from $S$. cerevisiae, under the $S$. cerevisiae PGK1 promoter. The native signal sequences of EGI and CBHI were able to direct the secretion of EGI and CBHI into the culture medium in $A$. gossypii. Although CBHI activity was not detected using 4methylumbelliferyl- $\beta$-D-lactoside as substrate, the protein was detected by Western blot using monoclonal antibodies. EGI activity was detectable, the specific activity being comparable to that produced by a similar EGI producing $S$. cerevisiae construct. More EGI was secreted than CBHI, or more active protein was produced. Partial characterization of CBHI and EGI expressed in A. gossypii revealed overglycosylation when compared with the native $T$. reese $i$ proteins, but the glycosylation was less extensive than on cellulases expressed in S. cerevisiae.
\end{abstract}

O. Ribeiro $\cdot$ L. Domingues $(\bowtie)$

IBB-Institute for Biotechnology and Bioengineering,

Centre of Biological Engineering, Universidade do Minho,

Campus de Gualtar,

4710-057 Braga, Portugal

e-mail: luciliad@deb.uminho.pt

M. Wiebe $\cdot$ M. Ilmén $\cdot$ M. Penttilä

VTT Technical Research Centre of Finland,

P.O. Box 1000, 02044 VTT Espoo, Finland
Keywords Ashbya gossypii $\cdot$ Recombinant protein production - Trichoderma reesei endoglucanase I. Trichoderma reesei cellobiohydrolase I . Cellulases heterologous expression

\section{Introduction}

The filamentous hemiascomycete Ashbya gossypii (Ashby and Nowell 1926) is a biotechnologically important producer of vitamin B2 (riboflavin; Demain 1972; Wickerham et al. 1946). Based on rDNA sequences, A. gossypii is more closely related to Saccharomyces cerevisiae than Neurospora crassa or Aspergillus nidulans (Wendland et al. 1999). A. gossypii has one of the smallest known eukaryotic genomes (Dietrich et al. 2004), a high homologous recombination efficiency allowing simple gene knockout strategies and precise positioning of gene constructs (Steiner et al. 1995; Wendland et al. 2000), extrachromosomal replication of plasmids bearing an autonomous replicator (Wright and Philippsen 1991), efficient introduction of heterologous DNA, and the fungus lacks the extensive duplication of chromosomal segments observed in S. cerevisiae, making it an extremely attractive candidate not only for riboflavin production, but also for the production of other industrial products such as recombinant proteins. However, little is known about the secretion of proteins by A. gossypii. Extracellular lipase has been detected, but activity was low in most conditions (Stahmann et al. 1997). An endo- $\beta$-1,4-glucanase (celA1) from Streptomyces halstedii has previously been expressed in A. gossypii with limited success (Althöefer et al. 2001). However, other filamentous fungi which do not secret large amounts of native enzymes/proteins have been found to still be good producers of recombinant proteins (Royer et al. 
1995). Since $A$. gossypii is a filamentous fungus, it might be expected to have efficient protein secretion, but its close relationship to $S$. cerevisiae may suggest limited secretion ability. We therefore expressed two cellulase genes from the filamentous fungus Trichoderma reesei in A. gossypii in order to assess its ability to produce and secrete recombinant proteins.

T. reesei is one of the most extensively studied cellulolytic organisms (Kubicek et al. 1993). It produces three types of enzyme activities needed for degradation of crystalline cellulose into glucose. These are cellobiohydrolases (EC 3.2.1.91), which act as exoenzymes and release cellobiose as a main product from crystalline cellulose, endoglucanases (EC 3.2.1.4), which have high affinity towards soluble cellulose derivatives and attack these by endo-action, and $\beta$-glucosidases (EC 3.2.1.21), which hydrolyse cellooligosaccharides and the disaccharide cellobiose into glucose.

T. reesei $\mathrm{CBHI}$ and endoglucanase I (EGI) are useful as model proteins for recombinant protein secretion, since they have been extensively studied in a variety of expression systems, as well as in $T$. reesei, and appear to be challenging for other organisms to produce. Expression of CBHI in Escherichia coli (Laymon et al. 1996; Teeri 1987) and yeast (Godbole et al. 1999; Penttilä et al. 1988; Reinikainen et al. 1992) has resulted in the production of either insoluble or low activity enzyme. Whereas $E$. coli produced misfolded CBHI peptide and/or CBHI inclusion bodies from which active enzyme could not be obtained, yeasts (S. cerevisiae, Pichia pastoris, and Yarrowia lipolytica) produced hyperglycosylated cellulases with low activity on either soluble substrates or amorphous cellulose. Even when $T$. reesei cellulases have been expressed in the efficient protein producing fungus Aspergillus oryzae, the activity of both CBHI and CBHII toward Avicel were relatively low when compared with the native enzymes, possibly because of differences in the modes of glycosylation (Takashima et al. 1998). Aspergillus niger var. awamori (Jeoh et al. 2008) produced functional enzyme, but it was more glycosylated than the native enzyme. Reports of successful expression of $T$. reesei $\mathrm{CBHI}$ from non- $T$. reesei hosts have been limited to one example of insect cell (Spodoptera frugipedra) production, following baculovirus transfection (von Ossowski et al. 1997).

Heterologous expression of EGI from $T$. reesei has been reported in S. cerevisiae and Y. lipolytica (Park et al. 2000; Penttilä et al. 1987b; Van Arsdell et al. 1987). The recombinant EGI produced by $S$. cerevisiae was hyperglycosylated and significantly larger than the native enzyme produced by $T$. reesei. There were similarities in the extent of hyperglycosylation, but differences in the types of glycosylation between $Y$. lipolytica and S. cerevisiae (Park et al. 2000). Apart from the differences in the extent of asparagine-linked glycosylation, recombinant EGI from $Y$. lipolytica appeared to be processed in a similar manner to the processing of the native enzyme by $T$. reesei. EGI seems to be slightly easier than CBHI to produce in nonTrichoderma recombinant hosts.

In this paper, we evaluate the potential of $A$. gossypii as a host for recombinant protein production, using the $T$. reese $i$ cellulases CBHI and EGI as model proteins. These proteins were chosen because they represent a challenge in recombinant protein production and have previously been expressed in several expression platforms. Because of the close genetic relationship between $A$. gossypii and $S$. cerevisiae, the comparison with expression in $S$. cerevisiae was of particular interest.

\section{Materials and methods}

Strains

A. gossypii ATCC10895 was obtained from Prof. P. Philippsen (Basel University) and maintained on agar (20 $\mathrm{g} \mathrm{l}^{-1}$ ) on Ashbya full medium (AFM; $10 \mathrm{~g} \mathrm{l}^{-1}$ tryptone, $10 \mathrm{~g} \mathrm{l}^{-1}$ yeast extract, $1 \mathrm{~g} \mathrm{l}^{-1}$ myo-inositol, $20 \mathrm{~g} \mathrm{l}^{-1}$ glucose). A. gossypii EGI (VTT D-101398) and A. gossypii CBHI (VTT D-101399) were obtained by transformation of ATCC10895 as described below. S. cerevisiae H81 ( $\alpha$, his3 1 l leu2-3,112 ura3-52 trp1-289 $\mathrm{Cyh}^{\mathrm{R}}$ ) was used as host to obtain comparable transformants of $S$. cerevisiae.

Spores were prepared by collecting 7-10 day-old mycelium from agar solidified plates, digesting the mycelia with zymolyase $\left(150 \mathrm{mg} \mathrm{ml}^{-1}\right)$ for $2 \mathrm{~h}$ and washing two times with a solution of $0.8 \%(w / v) \mathrm{NaCl}, 20 \%(v / v)$ glycerol, and $0.025 \%(v / v)$ Tween 20. Aliquots were suspended in the same solution and were stored at $-80^{\circ} \mathrm{C}$.

\section{Culture media}

LB medium supplemented with $100 \mu \mathrm{g}$ ampicillin $\mathrm{ml}^{-1}$ was used for $E$. coli cultivation. AFM supplemented with $200 \mu \mathrm{g} \mathrm{ml} \mathrm{m}^{-1} \mathrm{G} 418$ was used for the selection and maintenance of $A$. gossypii transformants containing the G418 resistance gene (Dünkler and Wendland 2007; Wendland et al. 2000). For regeneration of protoplasts, AFM with $20 \mathrm{~g}$ agar $1^{-1}$ was supplemented with $1 \mathrm{M}$ sorbitol. To detect cellulase-producing strains, agar solidified AFM was supplemented with $0.1 \%(w / v)$ barley $\beta$ glucan or $0.1 \%(w / v)$ carboxymethylcellulose (CMC). Synthetic complete defined medium (SCD) contained complete amino acid supplement (Sherman et al. 1986), yeast nitrogen base (Difco), $20 \mathrm{~g} \mathrm{l}^{-1}$ glucose, $1 \mathrm{~g} \mathrm{l}^{-1} \mathrm{CaCo}_{3}$, and $1 \mathrm{~g}^{-1}$ agar. 


\section{Plasmid construction}

Plasmid pMI519 (Fig. 1a) contained T. reesei egll cDNA and plasmid pMI514 (Fig. 1b) $T$. reesei cbh1 cDNA. Plasmids pMI519 and pMI514 were constructed from plasmids pTTc11 (Penttilä et al. 1987b) and pTTc1 (Teeri et al. 1987), respectively, together with B609 (Ruohonen et al. 1995), using the primers listed in Table 1. Both genes were under the control of the $S$. cerevisiae $P G K 1$ promoter and terminator obtained from plasmid pAJ401 (Saloheimo et al. 1994). The kanMX expression module was derived from a modified pUG6 vector, with the $\mathrm{kan}^{\mathrm{r}}$ gene from the E. coli transposon Tn903 under control of the TEF promoter from A. gossypii (Güldener et al. 1996; Wach et al. 1994) and the $A D H 1$ terminator from $S$. cerevisiae, to confer to the transformants resistance to the aminoglycoside antibiotic G418 (Jimenez and Davies 1980; Webster and Dickson 1983).

The control vector pMI516 without a cellulase insert was constructed by digesting pMI514 with PacI-AscI, filling in the ends using T4 polymerase and circularizing the $6.8 \mathrm{~kb}$ fragment.

\section{A. gossypii transformation and screening of transformants}

Transformation of $A$. gossypii was carried using protoplasts as described by Penttilä et al. (1987a), and selection was carried out on medium containing G418. Spores from single colonies were collected as described above and stored at $-80{ }^{\circ} \mathrm{C}$ for further analysis.

Transformants were screened in two ways. Initial screening was carried out by PCR using specific primers (Table 1). Template DNA was extracted by a rapid-miniprep method in which a piece of mycelium was transferred to a microfuge tube and lysed with lysis buffer (400 mM Tris$\mathrm{HCl}$ pH 8.0; 60 mM EDTA, pH 8.0; $150 \mathrm{mM} \mathrm{NaCl;} \mathrm{1 \%} \mathrm{w/v}$ $\mathrm{SDS}$ ) at room temperature for $10 \mathrm{~min}$. Proteins were precipitated by adding $150 \mu \mathrm{l}$ of $3 \mathrm{M}$ potassium acetate $\mathrm{pH} 4.8$, vortexing and centrifuging at $13,000 \times \mathrm{g}$ for $1 \mathrm{~min}$. The supernatant was transferred to a clean tube, and the DNA was precipitated by adding an equal amount of isopropanol. The sample was mixed by inverting and centrifuged at $13,000 \times g$ for $2 \mathrm{~min}$. The DNA was washed with ethanol $70 \%(v / v)$ and air-dried, before being dissolved in $50 \mu \mathrm{TE}$ buffer. PCR products were amplified with polymerase DNA2 MGII (Finnzymes) using $5 \mu$ sample DNA with, F5 buffer (Finnzymes), $2 \mu \mathrm{l} 2 \mathrm{mM}$ dNTP mix, $0.2 \mu$ oligo (5 nmol $\mu^{-1}$ ) EGI, CBHI, or G418-specific primers.

After the initial screening, mycelia from several colonies were grown in test tubes containing $5 \mathrm{ml}$ AFM supplemented with $200 \mu \mathrm{g} \mathrm{ml}^{-1} \mathrm{G} 418$ and samples of the culture medium assayed for secreted EGI or CBHI using 4methylumbelliferyl- $\beta$-D-lactoside (MULac, Sigma) as the substrate. Based on these results, two strains, VTT D101398 (expressing EGI) and VTT D-101399 (expressing $\mathrm{CBHI}$ ), were selected for further study.

S. cerevisiae H81 was transformed with the same plasmids as $A$. gossypii using the LiAc transformation method (Gietz et al. 1995) and screened in the same way as A. gossypii transformants.

\section{Culture conditions}

Transformed strains of $A$. gossypii were grown at $30^{\circ} \mathrm{C}$ or $24^{\circ} \mathrm{C}$ in flasks $(250 \mathrm{ml}$ flasks containing $50 \mathrm{ml}$ medium $)$ at $200 \mathrm{rpm}$ on AFM or SCD medium with $20 \mathrm{~g}^{-1}$ glucose as carbon source and $200 \mu \mathrm{g} \mathrm{ml} \mathrm{m}^{-1}$ G418. Samples were collected to determine cell concentration (absorbance measured at $600 \mathrm{~nm}$ ) and to obtain supernatant by filtration through glass fiber $\mathrm{GF} / \mathrm{C}$ filters or by centrifugation $\left(10 \mathrm{~min}\right.$ at $4,000 \times \mathrm{g}$ and $\left.4^{\circ} \mathrm{C}\right)$.

Dry weight was determined by converting OD at $600 \mathrm{~nm}$ with a conversion factor obtained from a calibration curve, where one unit OD at $600 \mathrm{~nm}$ was found to correspond to
Fig. 1 Plasmids for expression of $T$. reesei CBHI or EGI in $A$. gossypii. cDNA was inserted under the control of the PGK promoter and terminator from $S$ cerevisiae
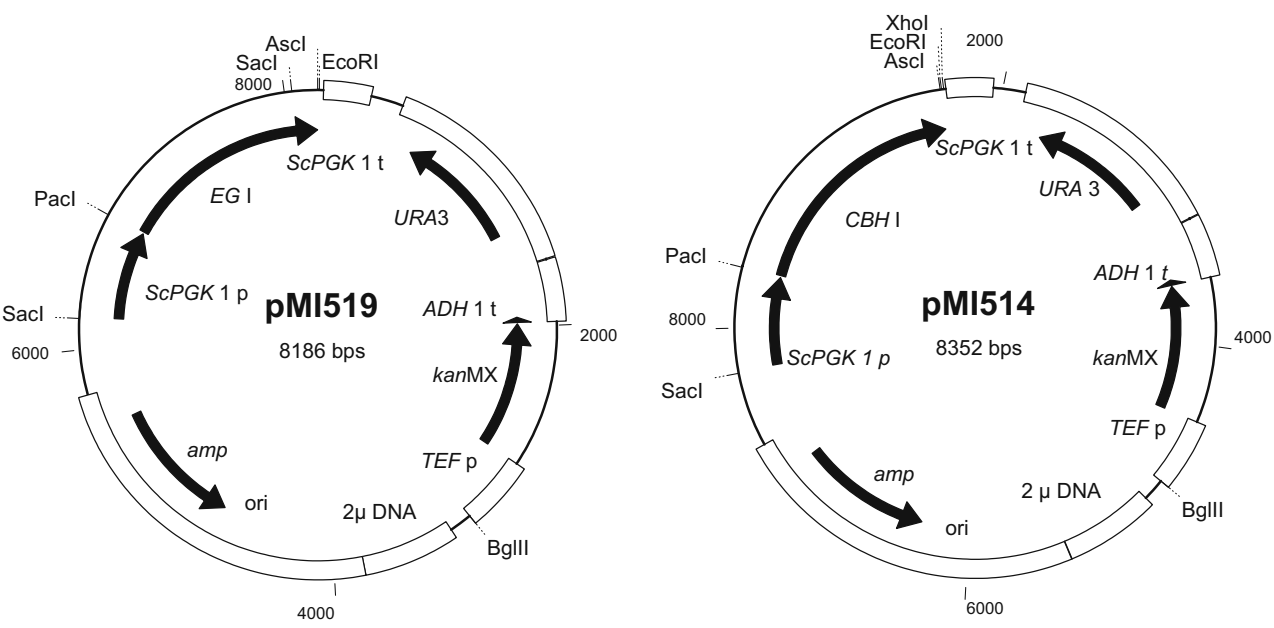
Table 1 Oligonucleotides used for construction of plasmids and strain screening

\begin{tabular}{|c|c|}
\hline Oligonucleotide & Sequence \\
\hline 373 EGL1 WT EcoRI-PacI-ATG & 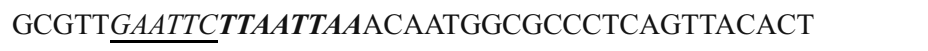 \\
\hline 374 EGL1 WT TAG-AscI-EcoRI & 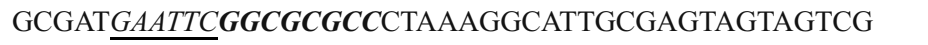 \\
\hline 379 ScPGK1prom-786 SacI + ApaI & 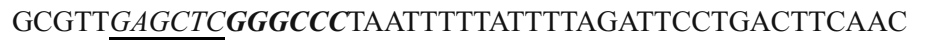 \\
\hline 380 ScPGK1prom EcoRI-PacI & 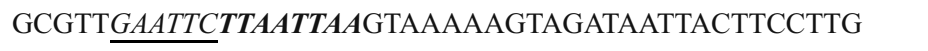 \\
\hline 387 CBH1 WT EcoRI-PacI-ATG & 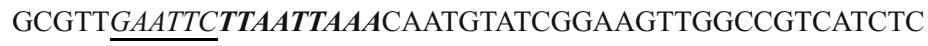 \\
\hline 392 CBH1 WT TAA-AscI-EcoRI & GCGATGAATTCGGCGCGCCTTACAGGCACTGAGAGTAGTAAGG \\
\hline
\end{tabular}

The restriction sites used for the construction of plasmids are highlighted in bold and underlined

$1.3 \mathrm{~g}^{-1} \mathrm{DW}$ for A. gossypii and $3.9 \mathrm{~g}^{-1} \mathrm{DW}$ for $S$. cerevisiae strains.

Cellulase activity on soluble substrates and insoluble substrates

Cellulase activities were determined using soluble MULac as substrate. The reaction consists in adding $50 \mu \mathrm{l}$ MULAc (4 $\mathrm{mM}$ in DMSO) to $50 \mu \mathrm{l}$ culture supernatant and incubating at room temperature. Reactions were stopped after $30 \mathrm{~min}$ incubation by adding $100 \mu \mathrm{l}$ of $1 \mathrm{M} \mathrm{Na}_{2} \mathrm{CO}_{3}$, and liberation of 4-methylumbelliferone (MU) was detected by fluorescence measurement (excitation wavelength= $355 \mathrm{~nm}$ and emission wavelength $=460 \mathrm{~nm}$ ) with a Varian Varioscan spectrofluorometer in a black, flat bottom microtiterplate. MU (Sigma) was used as a standard. Volumetric enzyme activity was measured as micromoles of MU formed per minute per liter under the assay conditions. Specific activity is given as micromoles MU formed per minute per gram dry weight mycelium. Protein concentrations in the cell-free broth were measured with Bio-Rad protein reagent, using bovine serum albumin as standard.

Cellulase activity was also detected by the presence of a yellow halo after Congo red staining of CMC or $\beta$-glucan containing agar solidified medium, according to the method of Teather and Wood (1982) using 0.1\% (w/v) CMC or $0.1 \%$ $(w / v) \beta$-glucan. To detect activity on agar solidified medium, $10 \mu \mathrm{l}$ of sample was loaded into small wells punctured in the agar and the Petri dishes were incubated at $30^{\circ} \mathrm{C}$ for $20 \mathrm{~h}$. Supernatants were first filtered through $0.22-\mu \mathrm{m}$ pore size nylon filters, concentrated, and washed with $50 \mathrm{mM}$ sodium acetate buffer $\mathrm{pH} 5.0$ in $10 \mathrm{kDa}$ Vivaspin concentrators (Sartorius). After $20 \mathrm{~h}$, the Petri dishes were flooded with Congo red $(0.1 \% \mathrm{w} / v)$ for $1 \mathrm{~h}$ and washed with $1 \mathrm{M} \mathrm{NaCl}$.

\section{Binding to Avicel}

For qualitative analysis of binding, $50 \mu \mathrm{l}$ culture supernatant containing $0.6 \mathrm{mg}$ of total protein, previously concentrated thirty-fold, were mixed with $12 \mathrm{mg}$ Avicel in $50 \mathrm{mM}$ sodium acetate $\mathrm{pH}$ 5.0. After incubation at $4{ }^{\circ} \mathrm{C}$ overnight with end-over end rotation, the mixtures were centrifuged at $13,000 \times g$ for $5 \mathrm{~min}$ to sediment the substrate and bound proteins. The cellulose was washed with $50 \mathrm{mM}$ sodium acetate $\mathrm{pH} 5.0$ and then with $50 \mathrm{mM}$ sodium acetate, $\mathrm{pH} 5.0$, containing $1 \mathrm{M} \mathrm{NaCl}$. The cellulose with bound proteins was mixed with $50 \mu \mathrm{l}$ SDS sample buffer $(250 \mathrm{mM}$ Tris- $\mathrm{HCl} \mathrm{pH}$ 6.8; $5 \% \mathrm{v} / v$ glycerol; $10 \mathrm{mg} \mathrm{ml}^{-1} \mathrm{SDS} ; 2.5 \%$ $v / v \beta$-mercaptoethanol; $0.05 \mathrm{mg} \mathrm{ml}^{-1}$ bromophenol blue) at $95^{\circ} \mathrm{C}$ for $3 \mathrm{~min}$, and the supernatant was analyzed by SDSPAGE in $12 \%(w / v)$ gels, followed by Western blot.

Enzymatic deglycosylation

To determine whether the recombinant cellulases were $N$ glycosylated, the proteins were digested with endoglycosidase $\mathrm{H}$ (Endo H, Roche) and PNGAseF (New England Biolabs) according to the manufacturer's instructions. In control samples, enzyme was replaced by water. Samples were incubated overnight, separated by $12 \%(w / v)$ SDSPAGE, and visualized by Western blot.

\section{Zymograms}

Zymograms were made according to the general procedure of Flint et al. (1994), to visualize enzyme activity and estimate approximate molecular weight. The stacking gel was $4 \%(w / v)$ polyacrylamide, and the separating gel contained $12 \%(w / v)$ polyacrylamide with $0.1 \%(w / v)$ CMC (Sigma) added prior to polymerization. After electrophoresis, the gels were washed in $1 \%(v / v)$ Triton X100 $(32 \times 200 \mathrm{ml}, 20 \mathrm{~min}$ per wash), soaked in sodium phosphate buffer $(50 \mathrm{mM}$, $\mathrm{pH} 6.5)$ to allow renaturation of the enzymes $\left(2 \mathrm{~h}\right.$ at $\left.4^{\circ} \mathrm{C}\right)$, and then incubated overnight at $37^{\circ} \mathrm{C}$ in sodium phosphate buffer (50 mM, pH 6.5). Following incubation, the gels were stained with $0.1 \%(w / v)$ Congo red for $1 \mathrm{~h}$, and then destained with sodium chloride (1 M) for a further $1 \mathrm{~h}$.

SDS-PAGE and Western blot analyses

Proteins were separated using denaturing SDS-PAGE with $12 \%(w / v)$ gels, as described by Laemmli (1970). Proteins 
were blotted onto 0.45 micron nitrocellulose membrane (Hybond) and assayed with monoclonal antibodies specific for T. reesei CBHI and EGI (Aho et al. 1991). The nitrocellulose membrane was blocked for $1 \mathrm{~h}$ in TBS (10 mM Tris- $\mathrm{HCl} \mathrm{pH} 8.0 ; 150 \mathrm{mM} \mathrm{NaCl}$ ) containing 5\% $(w / v)$ non-fat milk powder and $0.01 \%(v / v)$ Tween 20 (Sigma). After washing with TBST (10 mM Tris- $\mathrm{HCl} \mathrm{pH}$ $8.0 ; 150 \mathrm{mM} \mathrm{NaCl} ; 0.05 \% v / v$ Tween 20$)$, the monoclonal antibody was added. Goat anti-mouse Fc labeled with alkaline phosphatase was used as secondary antibody and BCIP/nitro-blue tetrazolium chloride substrate (Bio-Rad Laboratories, Hercules, CA) was used to visualize CBHI and EGI. The reaction was stopped by washing with distilled water and drying at room temperature. All washes and incubations were conducted at room temperature with gentle shaking.

Nucleotide sequence accession numbers

The nucleotide sequence for EGI is in GenBank database under accession number M15665 and CBHI under the number E00389.

\section{Results}

Transformation and heterologous expression of EGI and $\mathrm{CBHI}$ in A. gossypii

In order to express $T$. reesei cellulases CBHI and EGI in $A$. gossypii, protoplasts were transformed with plasmids pMI514, pMI519, and pMI516, with a transformation efficiency of 7080 transformants per microgram plasmid DNA.

Transformants with the highest cellulase activity, based on the MULac assay as described in Material and methods, were grown in batch cultures in rich AFM and SCD medium at $30^{\circ} \mathrm{C}$ or $24^{\circ} \mathrm{C}$ at $200 \mathrm{rpm}$. Production of cellulases did not reduce the specific growth rate of the recombinant strains, i.e., expression of EGI (or CBHI) did not appear to impose a metabolic load on the host. A. gossypii $\mathrm{CBHI}$ had a specific growth rate of $0.12 \pm 0.01 \mathrm{~h}^{-1}, A$. gossypii EGI of $0.11 \pm$ $0.01 \mathrm{~h}^{-1}$ and the negative control of $0.09 \pm 0.00 \mathrm{~h}^{-1}$ in AFM containing $20 \mathrm{~g} \mathrm{l}^{-1}$ glucose in flask cultures. Similarly, the production of $T$. reesei EGI did not reduce the specific growth rate of $S$. cerevisiae (Penttilä et al. 1987b).

Western blot analyses (Figs. 2 and 3) using monoclonal antibodies raised against the catalytic domain of the EGI or CBHI protein confirmed that $T$. reesei EGI (Fig. 3) and CBHI (Fig. 2) were present in the supernatant. CBHI was only detected by Western blot after removal of $N$-linked glycans, concentrating the protein to a single band (Fig. 2a, lane 2 and Fig. 2b, lane 4), demonstrating that the amount of secreted protein was very low.
Growth temperature may affect expression level, protein solubility, protein degradation, or cell viability, such that expression at a lower temperature increases the yield of the recombinant protein (Li et al. 2001; Shi et al. 2003). In $A$. gossypii, cellulase expression was not enhanced when the temperature was lowered from $30^{\circ} \mathrm{C}$ to $24^{\circ} \mathrm{C}$ (data not shown) either in rich AFM or in SCD medium.

Activity of recombinant cellulases produced in A. gossypii

Several methods were used to detect and evaluate whether the recombinant EGI and CBHI expressed in A. gossypii were in an active form. Secretion of active EGI was demonstrated by Congo red staining after incubation of concentrated sample of culture supernatant in $\mathrm{CMC}$ (Fig. 4a) or $\beta$-glucan (Fig. 4b) Petri dishes. The presence of a clearing zone indicated endoglucanase activity due to degradation of the substrate. Zymograms containing $0.1 \%$ $(w / v) \mathrm{CMC}$ in the resolving gel confirmed that EGI secreted by $A$. gossypii was active against CMC (Fig. 5, lane 5-6). Cellulases have a bimodal nature, with a cellulose binding domain (CBD) as well as an active site. We confirmed that the carbohydrate binding module was also present in the $A$. gossypii recombinant protein by incubation of recombinant EGI with Avicel. The protein was eluted with SDS-PAGE sample buffer and detected by Western blot analysis (Fig. 3, lane 3), confirming that both the cellulose binding domain and the active catalytic domain were present. CBHI activity was not detected in the plate assay or in zymograms containing $0.1 \%(w / v)$ Avicel, confirming that less CBHI was secreted than EGI or that the secreted protein was not active.

Heterologous expression of CBHI and EGI was also analyzed by measuring the activity on the soluble substrate MULac (Fig. 6). EGI activity in A. gossypii supernatant was maximal $\left(400 \mu \mathrm{mol} \mathrm{min}{ }^{-1} \mathrm{l}^{-1}, 1.3 \mathrm{nmol} \mathrm{m^{-1 }} \mu^{-1}\right.$ secreted protein) after $50 \mathrm{~h}$ growth in batch culture (Fig. 6a), at the end of the decelerating growth phase. In $S$. cerevisiae, maximal activity of $1,000 \mu \mathrm{mol} \mathrm{min} \mathrm{m}^{-1} \mathrm{l}^{-1}$ (2.2 $\mathrm{nmol} \mathrm{min}^{-1} \mu \mathrm{g}^{-1}$ secreted protein) was detected after $60 \mathrm{~h}$ (Fig. 6b), also as the cells entered stationary phase. Specific EGI production (activity per gram biomass) for both organisms was highest $\left(200-450 \mu \mathrm{mol} \mathrm{min}{ }^{-1} \mathrm{~g}^{-1}\right.$ dry weight) during exponential growth, as expected for proteins produced under the $P G K$ promoter (Fig. 6c). CBHI activity was not detectable in $A$. gossypii cultures with the MULac assay (Fig. 6a), but $S$. cerevisiae produced a maximum of $348 \mu \mathrm{mol} \mathrm{min} \mathrm{m}^{-1} \mathrm{1}^{-1}\left(1 \mathrm{nmol} \mathrm{min}{ }^{-1} \mu \mathrm{g}^{-1}\right.$ secreted protein; Fig. 6b). Although protease activity was negligible in the culture supernatant of $A$. gossypii cultures (data not shown), EGI appeared to be degraded during the stationary phase (Fig. 6), probably when cell lysis occurred, and intracellular proteases were released into the culture medium, as has sometimes been observed for recombinant proteins in other 


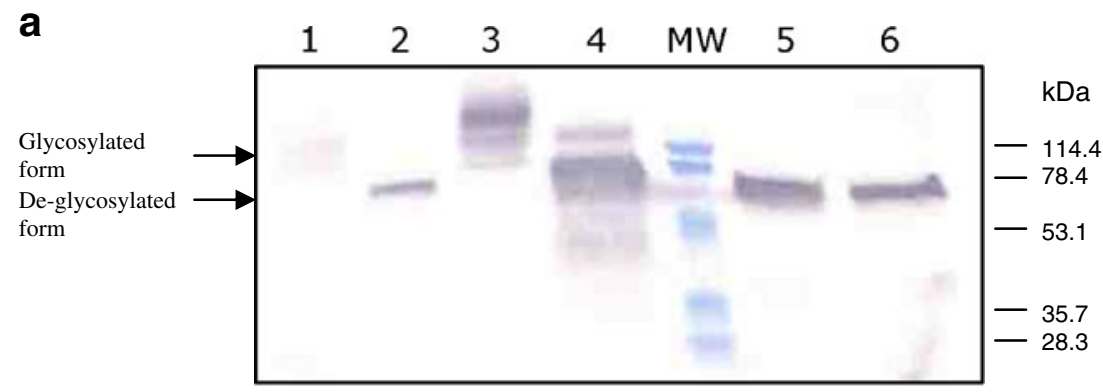

b

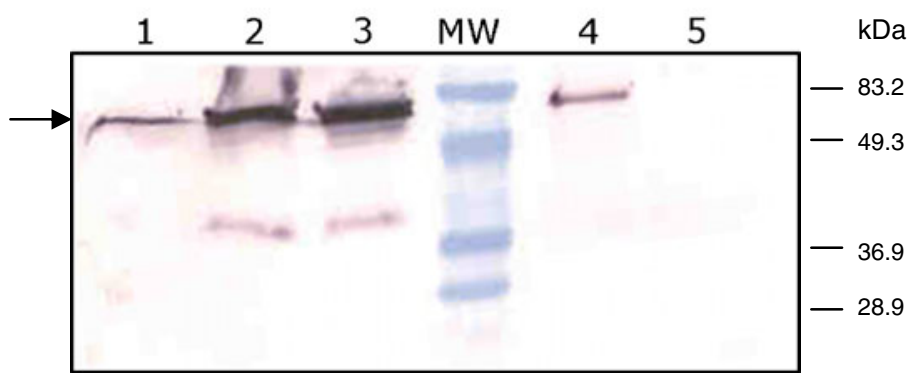

Fig. 2 Western blot analysis of recombinant CBHI treated with a endoglycosidase $\mathrm{H}$ or b PNGase F. a Lane 1, A. gossypii recombinant $\mathrm{CBHI}$ before Endo $\mathrm{H}$ treatment; lane 2, A. gossypii recombinant $\mathrm{CBHI}$ after Endo H treatment; lane 3, S. cerevisiae recombinant $\mathrm{CBHI}$ before Endo $\mathrm{H}$ treatment; lane 4, S. cerevisiae recombinant CBHI after Endo $\mathrm{H} ; M W$ molecular weight standard (sizes given at right); lane 5, T. reesei $\mathrm{CBHI}$ before Endo $\mathrm{H}$ treatment; lane 6, T. reesei $\mathrm{CBHI}$ after Endo $\mathrm{H}$

fungi (Archer et al. 1992; Broekhuijsen et al. 1993; Roberts et al. 1992; van den Hombergh et al. 1997).

Partial characterisation of recombinant cellulases secreted by $A$. gossypii

Zymogram analysis revealed that EGI secreted by $A$. gossypii had a higher molecular weight than the native enzyme from T. reesei (Fig. 5, lane 1), but was similar to the recombinant EGI in S. cerevisiae (Fig. 5, lane 2-4).

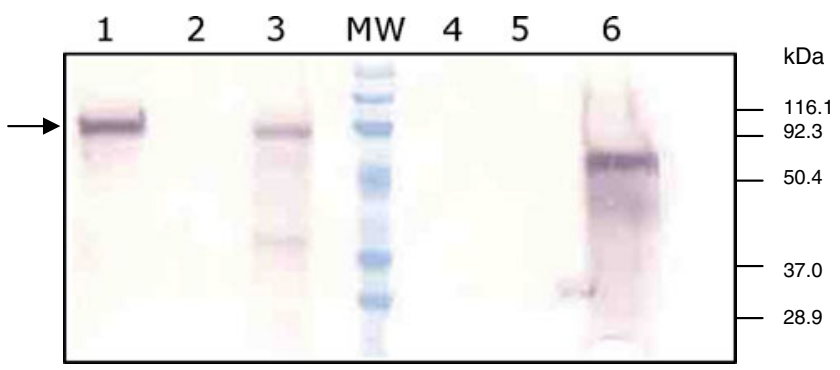

Fig. 3 Binding of EGI to Avicel. Six hundred micrograms of total protein was mixed with Avicel as described in Materials and methods. Legend: lane 1, recombinant protein that did not bind to Avicel; lane 2, washing Avicel with sodium acetate buffer $50 \mathrm{mM}, \mathrm{pH} 5.0$ and $1 \mathrm{M}$ $\mathrm{NaCl}$; lane 3, EGI eluted from Avicel; $M W$, molecular weight standard (sizes given at right); lane 4, supernatant of $T$. reesei EGI after incubation with Avicel; lane 5, washing Avicel with sodium acetate buffer $50 \mathrm{mM}, \mathrm{pH} 5.0$, and $1 \mathrm{M} \mathrm{NaCl}$; lane 6, T. reesei EGI eluted from Avicel. Protein bands are indicated with arrows treatment. b Lane 1, T. reesei $\mathrm{CBHI}$ without treatment; lane 2, T. reesei $\mathrm{CBHI}$ after PNGaseF treatment; lane 3, T. reesei $\mathrm{CBHI}$ incubated with water instead of PNGaseF; lane 4, A. gossypii CBHI after PNGaseF treatment; lane 5, A. gossypii $\mathrm{CBHI}$ without PNGaseF treatment. Lanes were loaded with $130 \mu \mathrm{g}$ total protein. Protein bands are indicated with arrows

Even though N-terminal sequence was not evaluated, the 20 amino acids composing the signal peptide sequence, being too small, would not account for the band shift observed in the zymogram (Fig. 5) or Western blot analysis (Figs. 2 and $3)$. The higher molecular weight indicated that the protein secreted by $A$. gossypii was probably glycosylated, as shown in Figs. 2 and 3, in which endoglycosidase treatment was used to remove glycans attached to the protein. Comparing lanes 2 and 5 of Fig. 5, S. cerevisiae appeared to produce more of the most highly glycosylated EGI than A. gossypii produced. After treating EGI from A. gossypii with PNGaseF (Plummer and Tarentino 1991), a minor band shift occurred (data not shown). PNGaseF was used to deglycosylate EGI produced in A. gossypii because it is known that EGI has a variety of glycosylation sites and that these have different susceptibilities to Endo $\mathrm{H}$ treatment. For example, Endo $\mathrm{H}$ is not able to completely deglycosylate recombinant EGI produced by $S$. cerevisiae (Penttilä et al. 1988; Van Arsdell et al. 1987). The reduction in molecular weight of $A$. gossypii produced EGI following enzymatic treatment was strong evidence that the recombinant enzyme was glycosylated (Trimble and Maley 1984; Maley et al. 1989), but not as extensively as EGI produced in S. cerevisiae.

Although only small amounts of CBHI were produced by $A$. gossypii, Western blot analysis after glycan removal, demonstrated that the CBHI produced by $A$. gossypii was also hyperglycosylated (Fig. 2a, lane 2 and Fig. 2b lane 4). 


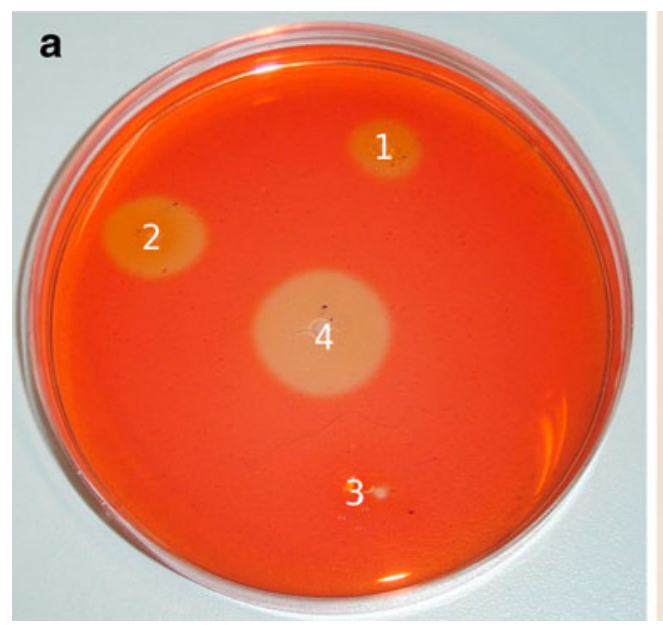

Fig. 4 Plate assay for detection of activity towards a carboxymethylcellulose $(\mathrm{CMC})$ and $\mathbf{b} \beta$-glucan. Thirty times concentrated protein samples, containing $60-120 \mu \mathrm{g}$ of total protein were loaded in small wells and stained with Congo red after $20 \mathrm{~h}$ incubation at $30^{\circ} \mathrm{C}$. a Wells contained 1 supernatant from $A$. gossypii expressing EGI grown in AFM; 2 supernatant from $S$. cerevisiae expressing EGI; 3

Hyperglycosylation was not as extensive as that observed in CBHI produced by $S$. cerevisiae, since both PNGaseF (Fig. 2b) and Endo $\mathrm{H}$ were able to deglycosylate the $A$. gossypii recombinant protein, resulting in a protein of similar molecular weight to the native $T$. reesei CBHI. In contrast, Endo $\mathrm{H}$ was only able to partially deglycosylate recombinant CBHI produced by S. cerevisiae (Fig. 2a, lane 4).

\section{Discussion}

The filamentous fungus $A$. gossypii has been used in the industrial production of the vitamin riboflavin. The exper-

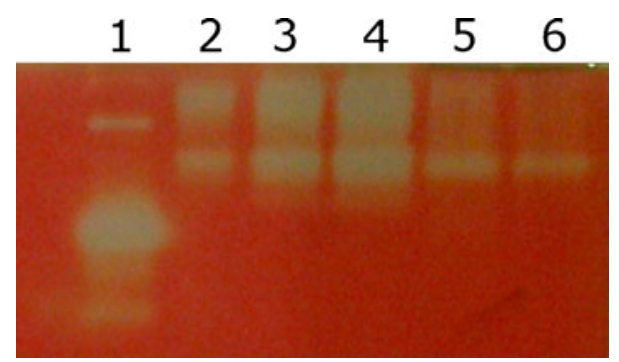

Fig. 5 Zymogram containing $0.1 \%(w / v)$ CMC incorporated in the SDS-PAGE gel, stained with Congo red, and washed with $1 \mathrm{M} \mathrm{NaCl}$. Legend: lane 1, $80 \mathrm{ng}$ of purified T. reesei EGI; lane 2, S. cerevisiae recombinant EGI, $70 \mathrm{~h}$ after inoculation three times concentrated (1.2 $\mathrm{g}$ g total protein); lane 3, S. cerevisiae recombinant EGI 15 times concentrated (6 $\mu \mathrm{g}$ total protein); lane $4, S$. cerevisiae recombinant EGI 30 times concentrated (12 $\mu \mathrm{g}$ total protein); lane 5, supernatant from a culture of $A$. gossypii expressing EGI, $62 \mathrm{~h}$ after inoculation (11 $\mu \mathrm{g}$ total protein); and lane 6, supernatant from an A. gossypii EGI producing culture, $43 \mathrm{~h}$ after inoculation $(6 \mu \mathrm{g}$ total protein). $A$. gossypii samples were concentrated thirty-fold

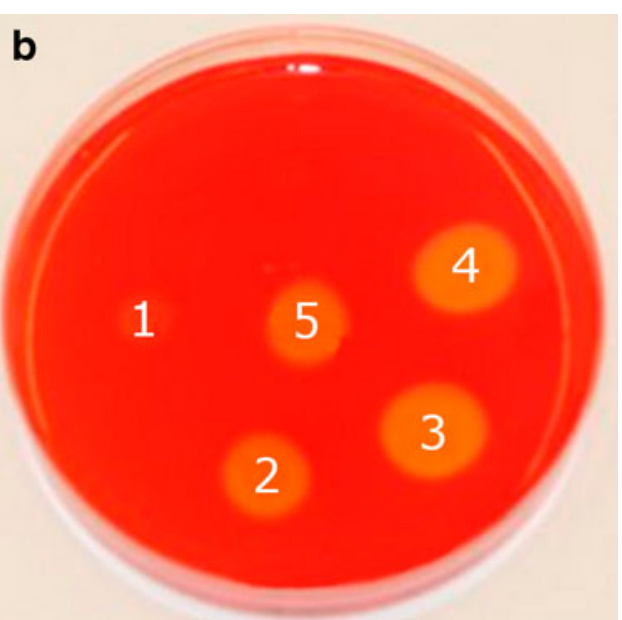

supernatant from the A. gossypii negative control strain; 4 native $T$. reesei EGI purified protein $(5 \mu \mathrm{g})$. Or $\mathbf{b}$ wells contained $l$ supernatant from A. gossypii expressing EGI grown in SCD medium; 2 supernatant from $A$. gossypii expressing EGI grown in AFM; 3 and 4 supernatant from two clones of $S$. cerevisiae expressing EGI; 5 native $T$. reesei EGI purified protein $(5 \mu \mathrm{g})$

imental tools available for use in $A$. gossypii together with its small genome and the regularity of filamentous growth and hyphal branching make it suitable for extensive study of polar (filamentous) growth. In this study, we take advantage of the same distinctive features to express and secrete heterologous cellulases under the $S$. cerevisiae $P G K 1$ promoter with $T$. reesei native signal peptides in $A$. gossypii. The transformation method used here was efficient, compared with that described by Kato and Park (2005), in which only ten to 20 transformants per microgram of plasmid DNA were obtained. Plasmids containing the $2-\mu \mathrm{m}$ replication origin were also used. Plasmids containing autonomously replicating sequence (ARS) such as the 2-micron plasmid replication origin and chromosomal replication origin (ARS1) from S. cerevisiae replicate freely in $A$. gossypii in contrast to lack of replication in other filamentous ascomycetes (Wright and Philippsen 1991), resulting in maintenance of higher copy number of the recombinant DNA than is generally obtained by integration.

Several aspects should be taken into account in recombinant proteins production, namely the promoter, signal sequence, culture conditions, and host genetic background. The most commonly used promoters in $A$. gossypii are AgGPD (Jiménez et al. 2005) and AgTEF (Kanamasa et al. 2007; Kato and Park 2005). Recently, Dünkler and Wendland (2007) reported the use of $S$. cerevisiae and A. gossypii MET3 promoters (regulated by methionine), contributing to the molecular toolbox available for A. gossypii. To our knowledge, this is the first time that the $S$. cerevisiae $P G K 1$ promoter has been used in $A$. gossypii. The PGK promoter is growth-related, and thus, 
Fig. 6 Average volumetric cellulase activities and dry weight (right axis) from supernatant of A. gossypii (a) and S. cerevisiae (b) growing in flasks in AFM at $30^{\circ} \mathrm{C}, 200 \mathrm{rpm}$. Activities were measured with the MULAc assay, described in Materials and methods. Data represent average \pm standard error of the mean obtained from three independent cultures. Strains were transformed with plasmids with genes for (solid triangle) CBHI, (open circle) EGI, or (solid square) an empty vector as the negative control. Dashed lines show dry weight (grams per liter) for the corresponding strain. c A. gossypii (open circle) and S. cerevisiae (solid circle) EGI specific activity per gram biomass during growth, represented as dry weight (dashed line)
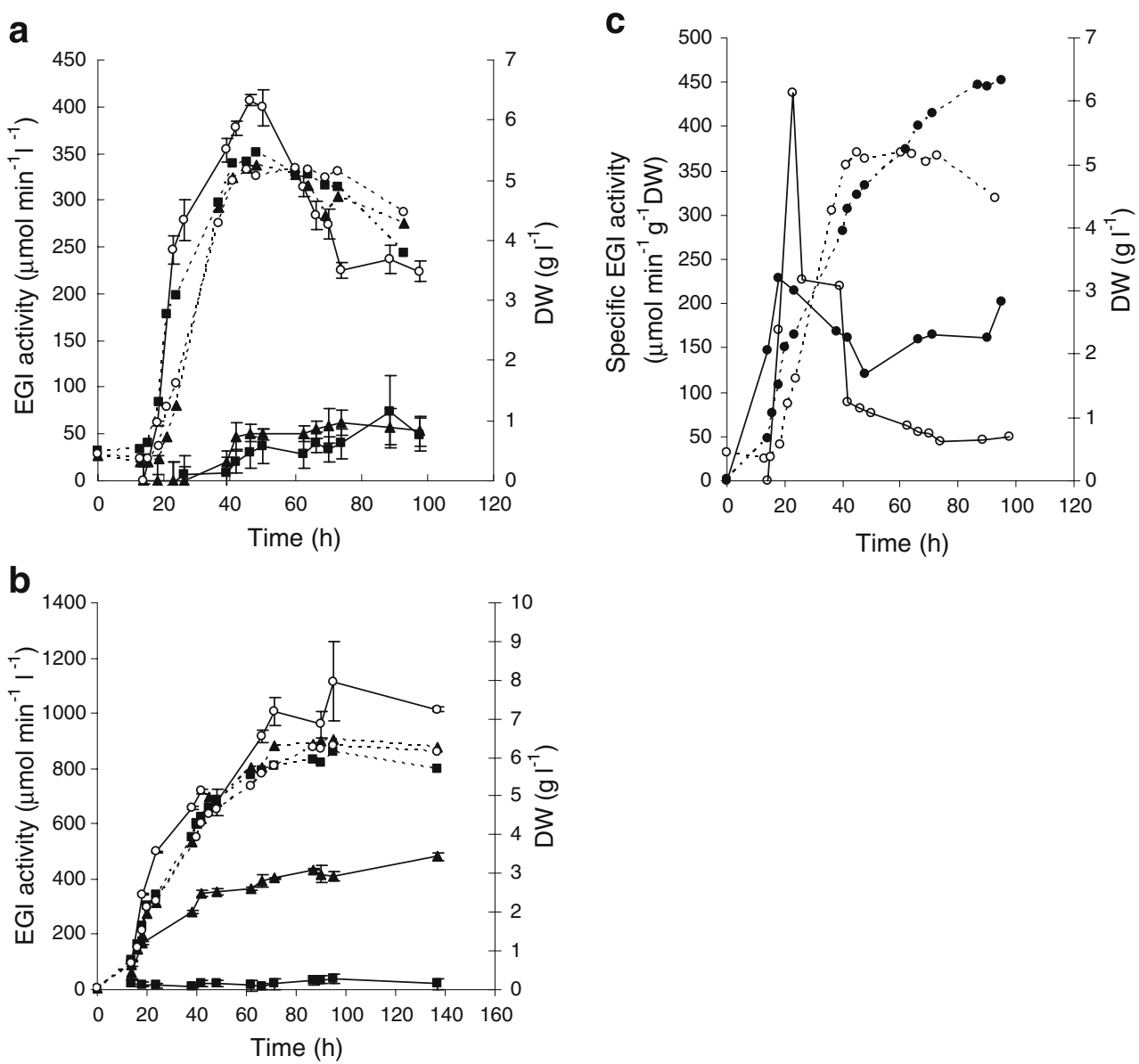

protein production would be unlikely to be affected by riboflavin production, which occurs primarily after substrate depletion (Karos et al. 2004). The recombinant EGI and $\mathrm{CBHI}$, carrying the heterologous, native signal sequences, entered the secretory pathway of A. gossypii, and functional EGI was found in the extracellular medium. EGI activity was detectable against both soluble and insoluble substrates. This was comparable to the endoglucanase activity against CMC illustrated by Althöefer et al. (2001) for $A$. gossypii expressing the endo- $\beta$-1,4-glucanase from $S$. halstedii. A. gossypii was not able to secrete $\mathrm{CBHI}$ protein to the same extent as EGI. CBHI production is always lower than other cellulases, including CBHII (Penttilä et al. 1988), possibly because the formation of disulfide bridges is important for correct folding (Boer et al. 2000). These results demonstrated the protein secretion by $A$. gossypii is comparable to $S$. cerevisiae and that a filamentous growth form is not sufficient to ensure high levels of protein secretion.

Both CBHs and EGs are glycoproteins containing heterogeneous $N$ - and/or $O$-linked glycans (Kubicek 1992) which may result in multiple protein bands in Western analysis. Glycosylation plays a role in the secretion of these cellulolytic enzymes, providing not only the optimal distance between the core and $\mathrm{CBD}$ but protecting the linker peptide from proteolytic attack (Clarke 1997; Srisodsuk et al. 1993). Similar to what has been observed in other host microorganisms, both EGI and CBHI were glycosylated by $A$. gossypii. The glycosylation was less extensive than in $S$. cerevisiae. A limitation in the extent of glycosylation is an advantage in the production of heterologous proteins whose properties may be adversely affected by extensive glycosylation. S. cerevisiae, in particular, forms high-mannose glycoproteins (Dean 1999; Gemmill and Trimble 1999). Filamentous fungi also have mannose rich glycans, but of more limited size than $S$. cerevisiae (Deshpande et al. 2008; Maras et al. 1997; Stals et al. 2004). In addition, filamentous fungi are known to secrete different glycosidases to the extracellular medium that may trim protein-linked glycans, adding heterogeneity to the glycan structure (Maras et al. 1999). Although A. gossypii is more closely related to $S$. cerevisiae than to other filamentous fungi, it appears to be able to limit the extent of protein glycosylation. Further analysis would be required to unveil the glycosylation pattern and degree of glycosylation performed by $A$. gossypii.

Although high levels of protein secretion are generally associated with filamentous growth, A. gossypii was more similar to the closely related yeast $S$. cerevisiae than to other filamentous fungi in its ability to produce and secrete 
EGI, demonstrating that filamentous growth alone is not sufficient to ensure good protein secretion. In comparison with the yeast $S$. cerevisiae, A. gossypii showed similar specific production of EGI, but less of CBHI. The expression of recombinant cellulases in A. gossypii provides opportunity for additional insights on the relationship between protein secretion and the filamentous growth form, while, as with $S$. cerevisiae, the low levels of protein secretion observed here do not necessarily limit the future development of $A$. gossypii as a heterologous protein production host.

Acknowledgements The financial support of Fundação para a Ciência e a Tecnologia (FCT), Portugal, is acknowledged: project AshByofactory PTDC/EBB-EBI/101985/2008 and grant SFRH/BD/ $30229 / 2006$ to Orquidea Ribeiro.

The authors declare that they have no conflict of interest.

\section{References}

Aho S, Olkkonen V, Jalava T, Paloheimo M, Bühler R, Niku-Paavola ML, Bamford DH, Korhola M (1991) Monoclonal antibodies against core and cellulose-binding domains of Trichoderma reesei cellobiohydrolases I and II and endoglucanase I. Eur J Biochem 200:643-649

Althöefer H, Pompeus M, Revuelta JL, Santos M, Jiminez A, Benito R, Santamaria R, Fernandez J (2001) Protein production using Ashbya gossypii. Patent WO/2001/023576

Archer DB, Mckenzie DA, Jeenes DJ, Roberts IN (1992) Proteolytic degradation of heterologous protein expressed in Aspergillus niger. Biotechnol Lett 14:357-362

Ashby SF, Nowell W (1926) The fungi of stigmatomycosis. Ann Bot 40:69-84

Boer H, Teeri T, Koiivula A (2000) Characterization of Trichoderma reesei cellobiohydrolase Cel7A secreted from Pichia pastoris using two different promoters. Biotechnol Bioeng 69:486-494

Broekhuijsen MP, Mattern IE, Contreras R, Kinghorn JR, van den Hondel CAMJJ (1993) Secretion of heterologous proteins by Aspergillus niger: production of active human interleukin-6 in a protease-deficient mutant by KEX2-like processing of a glucoamylase-HIL6 fusion protein. J Biotechnol 31:135-145

Clarke AJ (1997) Biodegradation of cellulose: enzymology and biotechnology. Technomic Publishing, Lancaster

Dean N (1999) Asparagine-linked glycosylation in the yeast Golgi. Biochem Biophys Acta 1426:309-322

Demain AL (1972) Riboflavin oversynthesis. Annu Rev Microbiol 26:369-388

Deshpande N, Wilkins MR, Packer N, Nevalainen H (2008) Protein glycosylation pathways in filamentous fungi. Glycobiology 18:626-637

Dietrich FS, Voegeli S, Brachat S, Lerch A, Gates K, Steiner S, Mohr C, Pöhlmann R, Luedi P, Choi S, Wing RA, Flavier A, Gaffney TD, Philippsen P (2004) The Ashbya gossypii genome as a tool for mapping the ancient Saccharomyces cerevisiae genome. Science 304:304-307

Dünkler A, Wendland J (2007) Use of MET3 promoters for regulated gene expression in Ashbya gossypii. Curr Genet 52:1-10

Flint HJ, Zhang J-X, Martin J (1994) Multiplicity and expression of xylanases in the rumen cellulolytic bacterium Ruminococcus flavefaciens. Curr Microbiol 29:139-143
Gemmill TR, Trimble RB (1999) Overview of $N$ - and $O$-linked oligosaccharide structures found in various yeast species. Biochem Biophys Acta 1426:227-237

Gietz RD, Schiestl RH, Willems AR, Woods RA (1995) Studies on the transformation of intact yeast cells by the LiAc/SS-DNA/PEG procedure. Yeast 11:355-360

Godbole S, Decker SR, Nieves RA, Adney WS, Vinzant TB, Baker JO, Thomas SR, Himmel ME (1999) Cloning and expression of Trichoderma reesei cellobiohydrolase I in Pichia pastoris. Biotechnol Prog 15:828-833

Güldener U, Heck S, Fielder T, Beinhauer J, Hegemann JH (1996) A new efficient gene disruption cassette for repeated use in budding yeast. Nucleic Acids Res 24:2519-2524

Jeoh T, Michener W, Himmel ME, Decker SR, Adney WS (2008) Implications of cellobiohydrolase glycosylation for use in biomass conversion. Biotechnol Biofuels 1:1-10

Jiménez A, Santos MA, Pompejus M, Revuelta JL (2005) Metabolic engineering of the purine pathway for riboflavin production in Ashbya gossypii. Appl Environ Microbiol 71:5743-5751

Jimenez A, Davies J (1980) Expression of a transposable antibiotic resistance element in Saccharomyces. Nature 287:869-871

Kanamasa S, Tajima S, Park EY (2007) Isocitrate dehydrogenase and isocitrate lyase are essential enzymes for riboflavin production in Ashbya gossypii. Biotechnol Bioprocess Eng 12:92-99

Karos M, Vilarino C, Bollschweiler C, Revuelta JL (2004) A genomewide transcription analysis of a fungal riboflavin overproducer. J Biotechnol 113:69-76

Kato T, Park EY (2005) Expression of alanine:glyoxylate aminotransferase gene from Saccharomyces cerevisiae in Ashbya gossypii. Appl Microbiol Biotechnol 71:46-52

Kubicek CP (1992) The cellulase proteins of Trichoderma reesei: structure, multiplicity, mode of action and regulation of formation. Adv Biochem Eng Biotechnol 45:1-25

Kubicek CP, Messner R, Gruber F, Mach RL, Kubicek-Pranz EM (1993) The Trichoderma cellulase regulatory puzzle: from the interior life of a secretory fungus. Enzyme Microb Technol 15:90-99

Laemmli UK (1970) Cleavage of structural proteins during assembly of head of bacteriophage T4. Nature 227:680-685

Laymon RA, Adney WS, Mohagheghi A, Himmel ME, Thomas SR (1996) Cloning and expression of full-length Trichoderma reesei cellobiohydrolase I cDNAs in Escherichia coli. Appl Biochem Biotech 57(58):389-400

Li Z, Xiong F, Lin Q, d'Anjou M, Daugulis AJ, Yang DS, Hew CL (2001) Low-temperature increases the yield of biologically active herring antifreeze protein in Pichia pastoris. Protein Expr Purif $21: 438-445$

Maley F, Trimble RB, Tarentino AL, Plummer TH Jr (1989) Characterization of glycoproteins and their associated oligosaccharides through the use of endoglycosidases. Anal Biochem 180:195-204

Maras M, De Bruyn A, Schraml J, Herdewijn P, Claeyssens M, Fiers W, Contreras R (1997) Structural characterization of $N$-linked oligosaccharides from cellobiohydrolase I secreted by the filamentous fungus Trichoderma reesei RUTC 30. Eur J Biochem 245:617-625

Maras M, van Die I, Contreras R, van den Hondel CA (1999) Filamentous fungi as production organisms for glycoproteins of bio-medical interest. Glycoconj J 16:99-107

Park CS, Chang CC, Ryu DD (2000) Expression and high-level secretion of Trichoderma reesei endoglucanase I in Yarrowia lipolytica. Appl Biochem Biotechnol 87:1-15

Penttilä M, Nevalainen H, Rättö M, Salminen E, Knowles J (1987a) A versatile transformation system for the cellulolytic filamentous fungus Trichoderma reesei. Gene 61:155-164

Penttilä ME, André L, Saloheimo M, Lehtovaara P, Knowles JK (1987b) Expression of two Trichoderma reesei endoglucanases in the yeast Saccharomyces cerevisiae. Yeast 3:175-185 
Penttilä ME, Andre L, Lehtovaara P, Bailey M, Teeri TT, Knowles JKC (1988) Efficient secretion of two fungal cellobiohydrolases by Saccharomyces cerevisiae. Gene 63:103-112

Plummer TH Jr, Tarentino AL (1991) Purification of the oligosaccharide-cleaving enzymes of Flavobacterium meningosepticum. Glycobiology 1:257-263

Reinikainen T, Rouhonen L, Nevanen T, Laaksonen L, Kraulis P, Jones TA, Knowles J, Teeri T (1992) Investigation of the function of mutated cellulose-binding domains of Trichoderma reesei cellobiohydrolase I. Proteins Struct Funct Genet 14:475-482

Roberts IN, Jeenes DJ, MacKenzie DA, Wilkinson AP, Sumner IG, Archer DB (1992) Heterologous gene expression in A. niger: a glucoamylase-porcine pancreatic prophospholipase A2 fusion protein is secreted and processed to yield mature enzyme. Gene 122:155-161

Royer JC, Moyer DL, Reiwitch SG, Madden MS, Jensen EB, Brown SH, Yonker CC, Johnston JA, Golightly EJ, Yoder WT, Shuster JR (1995) Fusarium graminearum A 3/5 as a novel host for heterologous protein production. Biotechnology (NY) 13:1479-1483

Ruohonen L, Aalto MK, Keränen S (1995) Modifications to the ADH1 promoter of Saccharomyces cerevisiae for efficient production of heterologous proteins. J Biotechnol 39:193-203

Saloheimo A, Henrissat B, Hoffrén AM, Teleman O, Penttilä M (1994) A novel, small endoglucanase gene, egl5, from Trichoderma reesei isolated by expression in yeast. Mol Microbiol 13:219-228

Sherman F, Fink GR, Hicks JB (1986) Methods in yeast genetics. Cold Spring Harbor LabPress, Plainview

Shi X, Karkut T, Chamankhah M, Alting-Mees M, Hemmingsen SM, Hegedus D (2003) Optimal conditions for the expression of a single-chain antibody $(\mathrm{scFv})$ gene in Pichia pastoris. Protein Expr Purif 28:321-330

Srisodsuk M, Reinikainen T, Penttilä M, Teeri TT (1993) Role of the interdomain linker peptide of Trichoderma reesei cellobiohydrolase I in its interaction with crystalline cellulose. J Biol Chem 268:20756-20761

Stahmann KP, Böddecker T, Sahm H (1997) Regulation and properties of a fungal lipase showing interfacial inactivation by gas bubbles, or droplets of lipid or fatty acid. Eur J Biochem 244:220-225

Stals I, Sandra K, Geysens S, Contreras R, Van Beeumen J, Claeyssens M (2004) Factors influencing glycosylation of Trichoderma reesei cellulases. I: postsecretorial changes of the $O$ - and $N$-glycosylation pattern of Cel7A. Glycobiology 14:713-724

Steiner S, Wendland J, Wright MC, Philippsen P (1995) Homologous recombination as the main mechanism for DNA integration and cause of rearrangements in the filamentous ascomycete Ashbya gossypii. Genetics 140:973-987

Takashima S, Iikura H, Nakamura A, Hidaka M, Masaki H, Uozumi T (1998) Overproduction of recombinant Trichoderma reesei cellulases by Aspergillus oryzae and their enzymatic properties. J Biotechnol 65:163-171

Teather RM, Wood PJ (1982) Use of Congo red-polysaccharide interactions in enumeration and characterisation of cellulolytic bacteria from bovine rumen. Appl Environ Microbiol 43:777-780

Teeri TT (1987) The cellulolytic enzyme system of Trichoderma reesei. Dissertation, University of Helsinki, VTT Publication No. 38

Teeri TT, Kumar V, Lehtovaara P, Knowles J (1987) Construction of cDNA libraries by blunt-end ligation: high-frequency cloning of long cDNAs from filamentous fungi. Anal Biochem 164:60-67

Trimble RB, Maley F (1984) Optimizing hydrolysis of $N$-linked highmannose oligosaccharides by endo-beta- $N$-acetylglucosaminidase H. Anal Biochem 141:515-522

Van Arsdell JN, Kwokl S, Schweickart VL, Ladner MB, Gelfandl DH, Innisl MA (1987) Cloning, characterization and expression in Saccharomyces cerevisiae endoglucanase I from Trichoderma reesei. Bio/technology 5:60-64

van den Hombergh JP, van de Vondervoort PJ, Fraissinet TL, Visser J (1997) Aspergillus as a host for heterologous protein production: the problem of proteases. Trends Biotechnol 15:256-263

von Ossowski I, Teeri T, Kalkkinen N, Oker-Blom C (1997) Expression of a fungal cellobiohydrolase in insect cells. Biochem Biophys Res Commun 233:25-29

Wach A, Brachat A, Pöhlmann R, Philippsen P (1994) New heterologous modules for classical or PCR-based gene disruptions in Saccharomyces cerevisiae. Yeast 10:1793-1808

Webster TD, Dickson RC (1983) Direct selection of Saccharomyces cerevisiae resistant to the antibiotic G418 following transformation with a DNA vector carrying the kanamycin-resistance gene of Tn903. Gene 26:243-252

Wendland J, Pohlmann R, Dietrich F, Steiner S, Mohr C, Philippsen P (1999) Compact organization of rRNA genes in the filamentous fungus Ashbya gossypii. Curr Genet 35:618-625

Wendland J, Ayad-Durieux Y, Knechtle P, Rebischung C, Philippsen P (2000) PCR-based gene targeting in the filamentous fungus Ashbya gossypii. Gene 242:381-391

Wickerham L, Flickinger MH, Johnston RM (1946) The production of riboflavin by Ashbya gossypii. Arch Biochem 9:95-98

Wright MC, Philippsen P (1991) Replicative transformation of the filamentous fungus Ashbya gossypii with plasmids containing Saccharomyces cerevisiae ARS elements. Gene 109:99-105 